\title{
Moving on assisted migration
}

\section{Experts who once disregarded it as a nutty idea are now working out the nuts and bolts of a conservation taboo: relocating species threatened by climate change. Emma Marris reports.}

T he quino checkerspot butterfly, a brown, red and black airborne quilt just a few centimetres across, is an endangered California subspecies being hit hard by climate change. These insects don't like it too hot and dry, and they might have moved slowly en masse towards cooler, wetter climes had the Los Angeles sprawl not been in their way.

But with a little help - a few cocoons toted into the mountains, or north around the city - this species could perhaps re-establish itself. Experts are now giving serious attention to this previously touchy topic: the notion of moving species threatened with extinction by a changing climate into areas where they have never been before.

This August in Milwaukee, Wisconsin, a group of scientists, lawyers, land managers, economists and ethicists gathered to discuss the nuts and bolts of breaking a conservation taboo. Whether called 'assisted migration', 'assisted colonization' or 'managed relocation', the idea of manually relocating species is decidedly controversial, and some in the Milwaukee working group feel it would most likely be a disaster.

The main worry is that those moved to new places will do too well and become invasive pests. Relocated species might also bring disease, or they could fail to thrive after a move that leaves behind their current ecosystem companions. And from a purely ideological perspective, interfering with nature in this way is, for many, at odds with conservation's purpose of preserving native assemblages.

But with research beginning to turn up more and more evidence that climate change is already driving species towards extinction when they can't disperse to more suitable areas, assisted migration has evolved in just a few years from a theoretically interesting notion to a realistic possibility.

\section{ALREADY IN TRANSIT}

Interested parties are now scrambling to envision how it would work on the ground. "The community was not in the right place to be talking about this issue until recently,"

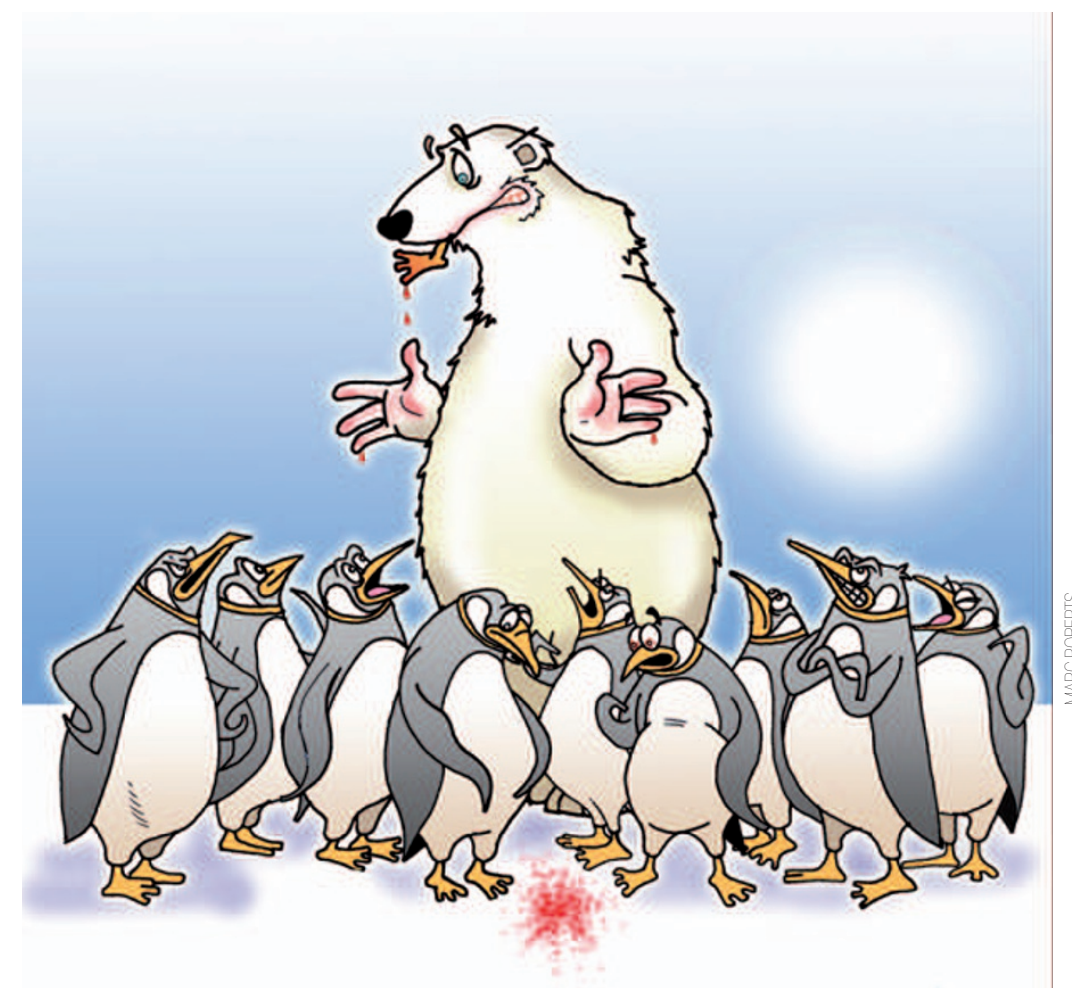

says Jessica Hellman, a biologist at the University of Notre Dame, Indiana, and one of the four leaders of the Milwaukee working group. "The idea is out there, and now we are really at a stage where we need to say something more concrete."

Stephen Schneider, a climatologist at Stanford University in California and a key contributor to the Intergovernmental Panel on Climate Change (IPCC), attended the working group. Schneider hopes its output will be similar to IPCC reports in providing information to assist decision-making without giving direct advice on whether or not to relocate threatened species. "We need a set of best practices, a priority scheme on what gets managed and what just gets left [to] adapt on its own," he says.

The working group hopes to release a report by fall 2009 with some advice on when and how - if at all - to move species. Moves of all sorts will be considered, from planting trees a few hundred kilometres north of their historical range to 'rewilding' North America with cheetahs and camels. But even those in favour of assisted migration generally insist it won't go as far as the oft-quoted example of transporting polar bears to the Antarctic, a move that could transfer the threat of extinction to the region's native penguins.

At least on a limited scale, it seems that assisted migration is already happening. One of the most well-known cases is the transfer of Torreya taxifolia, a Florida conifer with a tiny range that many believe survives there only due to historical accident. In a desperate bid to protect their beloved species, a group of botanists and environmentalists who call themselves the Torreya Guardians have established a volunteer seed-planting campaign to move it northwards. On 3 August, they planted 31 Torreya taxifolia seedlings in North Carolina ${ }^{1}$.

But some of the relocation taking place is perhaps less intentional. Sebastian Van der Veken of the Catholic 
University of Leuven in Belgium and co-authors recently found that the 'commercial ranges' of 357 native European plants, the places where they were available for purchase at nurseries, were on average 1,000 kilometres further north than their 'natural ranges'. "While conservation biologists actively debate whether we should intentionally provide 'assisted migration," they conclude, "it is clear that we have already done so for a large number of species."

With all this activity, specialists will have to work fast if they are to influence how society goes about moving species around. A recent commentary in Science ${ }^{3}$ gets things started with a flow chart for selecting appropriate species. Translocation should be attempted, according to the chart, only with species that have "a high risk of decline or extinction under climate change", when the translocation is "technically possible", and when "the benefits of translocation outweigh the biological and socioeconomic costs and constraints".

\section{RETHINKING CONSERVATION}

Camille Parmesan, an expert on the ecological effects of climate change at the University of Texas at Austin and a co-author of the Science paper, is raring to get started. "I'm going to propose to the US Fish and Wildlife Service that assisted colonization should be considered for the endangered quino checkerspot butterfly," she says. "I think it's a perfect candidate for assisted movement to higher altitudes. It's a very small butterfly and it doesn't really ever get abundant enough to severely impact the plant populations it uses; it doesn't really interact with other butterflies, and it's easy and cheap to move around to new places."

To do this, though, might require some tweaking of environmental law. Assisted migration may well get its feet tangled in the Endangered Species Act, the United States's flagship biodiversity protection law, along with hundreds of other state, national and international laws on species protection, invasive-species avoidance, and import and export of biological material - even game statutes. "I think the Endangered Species Act would have to be amended to allow movement of endangered species outside of their native range," says Parmesan.

Legal scholars are barely getting their toes wet thinking it all out, and policies specifically addressing assisted migration don't yet exist. "What we are considering here is not just the implication of assisted migration for the existing legal landscape but to imagine a new regime: what would it do to accommodate or prevent assisted

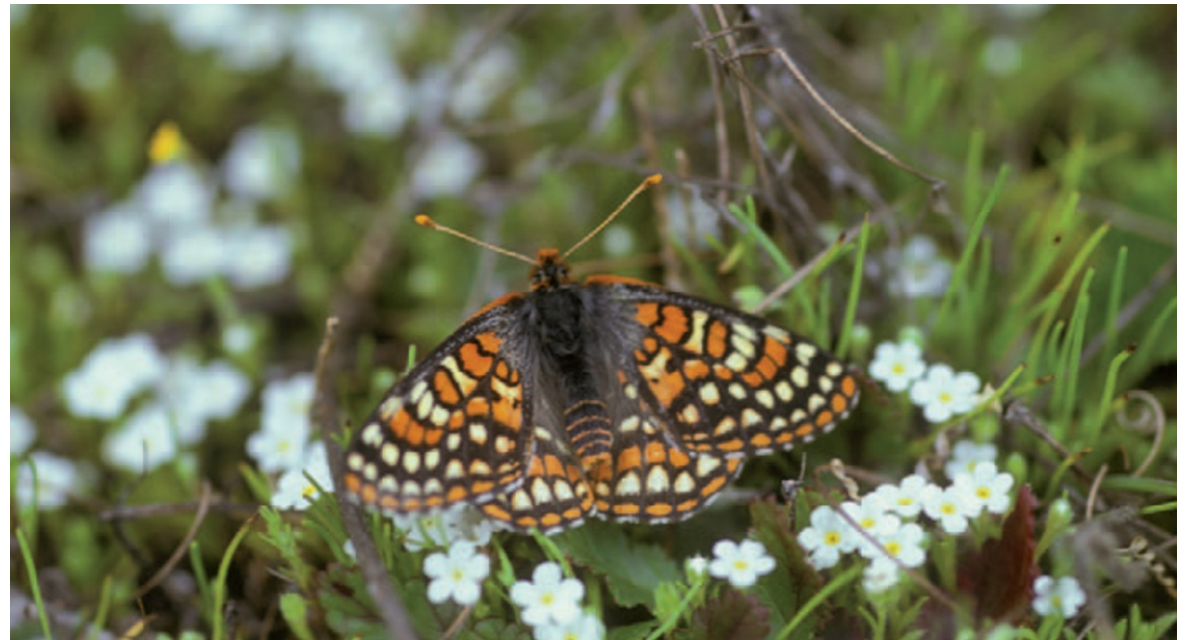

Quino checkerspot butterfly.

migration?" says Alejandro Camacho, a law professor at Notre Dame who attended the first working-group meeting.

"It is illegal to do a lot of things in this country," adds Dov Sax, an invasive-species expert at Brown University in Providence, Rhode Island, another working-group leader. "You could easily make it illegal to move species around. I am agnostic, without a lot more information, about whether that would be a good thing or not."

\section{"I think more than anything the fear of assisted migration is about who we think we are, what we think our place in the world is. It's about the hubris of thinking we can just reorganize life on earth.'}

Jessica Hellman

Some of the legal implications are startling, and not just for lawyers. "A lot of environmental laws conserve and preserve what is there, and to a limited extent, restore the past," says Camacho. "This would change that. I think the alternative goal would be based on the value of biodiversity writ large. We're saying now that to serve biodiversity, we might want to move away from preservation."

This is heady stuff for many conservationists deeply attached to the notion of preservation. "I think more than anything the fear of assisted migration is about who we think we are, what we think our place in the world is," says Hellman.
"It's about the hubris of thinking we can just reorganize life on earth."

An alternative view is that assisted migration isn't about humans remaking the earth to their liking, but rather is about manipulating it to look as though we aren't even here. "Humans have dominated the landscape to such an extent that natural dispersal cannot take place in many areas," says Parmesan. Los Angeles is a pretty big ocean for a three-centimetre-wide butterfly to cross. Some species can't even cross a highway. "It is in those cases that assisted migration makes the most sense: on species that would have been able to do it on their own, if not for humans."

Of course, there wouldn't be any need for such large-scale dispersal without anthropogenic climate change, so it is impossible to erase our footprints entirely. Species have moved around plenty in their histories as conditions changed. This time, we changed the conditions.

The upshot of all of this? More research, more reports, and probably in short order. "Although people have been kicking these ideas around for a while, we have reached a critical mass of concern," says Sax. "My suspicion is that in ten years this will be a major subject of research."

\section{Published online: 28 August 2008}

\section{doi:10.1038/climate.2008.86}

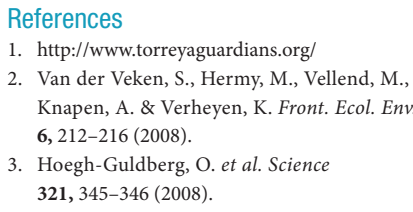

Emma Marris is a correspondent for Nature based in Columbia, Missouri. 